\title{
Reconstruction of the Congenital Nasal Bone Hypoplasia with Rib Cartilage Graft: Aesthetic, Functional and Psychological Aspects
}

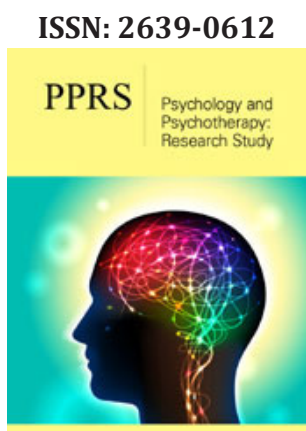

*Corresponding author: Tugui DO, Medical Student, University of Medicine and Pharmacy "Gr. T. Popa”, Iasi, Romania

Submission: 睓 November 05, 2019

Published: 侮 November 13, 2019

Volume 3 - Issue 1

How to cite this article: Tugui DO Zelinschi DC, Tătaru RC, Mazilu G. Reconstruction of the Congenital Nasal Bone Hypoplasia with Rib Cartilage Graft: Aesthetic, Functional and Psychological Aspects. Psychol Psychother Res Stud. 3(1).PPRS.000552.2019.

DOI: 10.31031/PPRS.2019.03.000552

Copyright@ Tugui D0, This article is distributed under the terms of the Creative Commons Attribution 4.0 International License, which permits unrestricted use and redistribution provided that the original author and source are credited.

\author{
Tugui D0 ${ }^{1 *}$, Zelinschi DC ${ }^{2}$, Tătaru RC $^{1}$ and Mazilu G ${ }^{3}$ \\ ${ }^{1}$ Medical Student, University of Medicine and Pharmacy “Gr. T. Popa”, Iasi, Romania \\ ${ }^{2}$ Medical Doctor, University of Medicine and Pharmacy “Gr. T. Popa”, Iasi, Romania \\ ${ }^{3}$ Aesthetic and Plastic Surgeon, Arcadia Medical Center, Iasi Romania
}

\begin{abstract}
Physical appearance, nowadays, has, not only a very great psychological impact on how each person self-perceives, but also guides a very important part of the way things are going in everyone's life. To accomplish to prove this aspect, we resorted to conduct a case study, following to emphasize the secondary psychological evolution of a rhinoplasty intervention on an 18-year-old female patient. Thus, after the intervention, it was shown that, during the postoperative period, besides a very good medical evolution, the patient also improved her psychological self-perception. The particularity of this case consists both in the early age of the patient and in the difficulty of the chosen procedure for the aesthetic nose correction.
\end{abstract}

Keywords: Psychological impact; Self-perception; Rhinoplasty; Nose hypoplasia; Rib cartilage; Nasal turbinates hypertrophy

\section{Introduction}

The nasal bones are a pair of small elongated bones which form the bridge of the nose. The ossification process begins in the third month of intra-uterine life, starting from one center. Manning \& Singh [1] sustain that during the first year of life, the width of the nasal bridge has reached $75 \%$ of the normal adult size and the subsequent growth occurs by depositing the surface of the bone at the medial wall of the orbital cavities, and not by increasing the internal sutures. The nasal bone growth deficit is called nasal bone hypoplasia. Sometimes, this may be an intra-uterine sign of down syndrome [2], but, most of the times, nasal bone hypoplasia is a rare congenital disorder, which seems to be related to other anomalies and can lead to complications such as hypertrophy of the nasal turbinates or septal deviation. This disorder becomes more visible as the patient ages and, clinically, presents the following aspects: paucity, atrophy or underdevelopment of skin, subcutaneous tissue, muscles and cartilage or bone.

\section{Case Report}

The presentation is about the case of an 18-year-old female patient, who was hospitalized on request at the private hospital "Arcadia Medical Center Iasi", Plastic and Aesthetic section, having as main dissatisfaction the shape of her nose. The clinical examination reveals septal deviation and bilateral nasal turbinates hypertrophy, which seem to have as root cause the underdevelopment of the nasal bone. Due to these complications, the patient also complained, besides the appearance, of sleep apnea and nasal congestion. The treatment consisted in surgical intervention, practicing total opened rhinoplasty. Jugpal [3] considers that this intervention modifies the functional properties and aesthetic aspects of the nose through operative manipulation of the skin, underlying cartilage, bone and lining, making a small incision in the columella between the nostrils and continuing with additional incisions inside the nose. The next step was the paramedian osteotomy followed by septoplasty, nasal turbinectomy, alar cartilages folding and reconstruction of the column and the dorsal part of the septum with autologous rib graft. The most interesting part was the augmentation of the nasal dorsum with free rib cartilage graft, wrapped in temporary fascia (DCF-graft). Finally, 
the doctor proceeded to fix the anterior septum to the anterior nasal spine and to suture the mucosa with resorbable thread. The immobilization was done with a splint for protection, but it may also be indicated to reduce bruising and edema [4].

\section{Discussion}

Often, it happens that the patients have as their main motivation the aesthetic aspect compared to the functional one. Anterior psychoanalytic studies [5,6] show that dissatisfaction with the physical aspect is interpreted as an inner conflict, these patients being more obsessive and narcissistic [7]. However, our case highlights that, due to the nature of the women's status in society, the aesthetic aspect can have a greater psychic impact on the female sex. At the same time, it has been shown that patients who wish to have rhinoplasty intervention are more prone to psychological damage compared to candidates for other aesthetic procedures. This fact can be explained by the "daily mirror", which reminds the patient of the deformity perceived as the cause of the mental suffering [4]. The key point at which the patient decides to go to a plastic surgeon is when self-esteem decreases or when they assume the role of "motivated" and they simply want to change.

\section{Conclusion}

The particularity of this case consists both in the early age of the patient and in the difficulty of the chosen procedure for the aesthetic nose correction. Due to the rib cartilage advantages such as the ease of modeling and the absence of resorption and distortion, general long-term complications of a patient who had an autologous rib cartilage rhinoplasty were found to be significantly reduced compared to other types of interventions. Also, following the patient postoperatively, from a psychological point of view, there was an observable increase of self-perception, an improvement of mood and a much more positive attitude.

\section{References}

1. Manning KP, Singh SD (2007) Hypoplasia of the nasal bones. The Journal of Laryngology and Otology 91: 1085-1091

2. Odibo AO, Sehdev HM, Stamilio DM, Cahill A, Dunn L, et al. (2007) Defining nasal bone hypoplasia in second-trimester down syndrome screening: Does the use of multiples of the median improve screening efficacy? Am J Obstet Gynecol 197(4): 361.e1-361.e4.

3. Jugpal A (2019) Basic open rhinoplasty.

4. Tasman AJ (2007) Rhinoplasty indications and techniques. GMS Curr Top Otorhinolaryngol Head Neck Surg 6: Doc09.

5. Hill G, Silver AG (1950) Psychodynamic and motivations for plastic surgery. Psychol Med 12(6): 345-355.

6. Linn L, Goldman IB (1949) Psychiatric observations concerning rhinoplasty. Psychosom Med (5): 307-314

7. Dinis PB, Dinis M, Gomes A (1998) Psychological consequences of nasal aesthetic and functional surgery: a controlled prospective study in an ENT setting. Rhinology 36(1): 32-36.

For possible submissions Click below: 